\title{
Forensic Pathology of Canadian Bread Wheat: The Case of Tan Spot
}

\author{
Lakhdar Lamari, Brent D. McCallum, and Ron M. dePauw
}

First author: Department of Plant Science, University of Manitoba, Winnipeg, MB, R3T 2N2, Canada; second author: Cereal Research Centre, Agriculture and Agri-Food Canada, Winnipeg, MB, R3T 2M9 Canada; and third author: SPARC, Agriculture and Agri-Food Canada, Swift Current, SK, S9H 3X2, Canada. Accepted for publication 7 October 2004.

\begin{abstract}
Lamari, L., McCallum, B. D., and DePauw, R. M. 2005. Forensic pathology of Canadian bread wheat: The case of tan spot. Phytopathology 95:144-152.

Pyrenophora tritici-repentis causes necrosis and chlorosis in its wheat host. Susceptibility to races 2 (necrosis) and 5 (chlorosis) of the pathogen is known to be mediated by Ptr ToxA and Ptr ToxB, respectively. Sensitivity to each toxin is controlled by a single dominant and independently inherited gene. We used sensitivity to Ptr ToxA and Ptr ToxB as two genetic markers to investigate the origin and the state of tan spot susceptibility in Canadian Western Red Spring (CWRS) wheat over a period of more than a century. Sensitivity to Ptr ToxA, the toxin produced by nearly all isolates of the pathogen collected in the past 20 years in western Canada, appears to have been present in the first major cultivar, Red Fife, grown massively in the late 1800 s. Sensitivity then was transmitted unknowingly into Canadian wheat lines through extensive use of back-

tivity to Ptr ToxA, which nearly disappeared from cultivars grown in western Canada in the 1950s, was reintroduced in the 1960s and unintentionally bred into many of the present-day cultivars. Sensitivity to Ptr ToxB, a toxin rarely found in isolates from western Canada, appeared with the release of Thatcher in 1934 and was transferred to many cultivars through backcross programs. In spite of large areas planted to Ptr ToxAand Ptr ToxB-sensitive cultivars over decades, tan spot epidemics remained sporadic until the 1970s. The results of this study raise the problem of the narrowing genetic base of CWRS wheat lines and the potential for unanticipated threats from plant pathogens. The intercrossing of genetically diverse material in one Canadian wheat breeding program resulted in the release of several modern cultivars with resistance to tan spot. The absence of wild-type Ptr ToxB-producing isolates in western Canada remains unexplained, given that sensitivity to Ptr ToxB was present continuously in western Canadian cultivars grown on vast areas for more than 70 years.
\end{abstract} crossing to maintain the Marquis-Thatcher breadmaking quality. Sensi-
Tan spot of wheat, caused by the ascomycete Pyrenophora tritici-repentis (Died.) Drechs. (anamorph Drechslera triticirepentis (Died.) Shoemaker), is a major disease of wheat worldwide, including on the Canadian Prairies, where it was reported in the 1930s (9-11) then reached epidemic proportions on a regular basis in the mid-1970s (52).

$P$. tritici-repentis became a problem in the major wheat-growing areas at about the same period. Rees and Platz (43) suggested that, because $P$. tritici-repentis survives on crop debris, the trend away from stubble burning was a major factor in the development of tan spot in Australia. It is commonly accepted that changing agronomic practices toward soil conservation have resulted in increased inoculum levels and higher disease incidence (43).

Considerable progress recently was achieved in our understanding of host-pathogen interactions in tan spot of wheat. In less than two decades, a great deal of the genetics of host resistance and physiologic variation in the pathogen has been explained. To date, eight races have been characterized on three effective host differential genotypes (34). Virulence of the races was shown to be mediated by host-specific toxins. Three such toxins have been identified and characterized. To avoid confusion, the naming of the toxins of $P$. tritici-repentis follows a nomenclature agreed upon by $\tan$ spot researchers (5). Ptr ToxA and Ptr ToxB were found to be proteins $(3,53,54)$ and their encoding genes cloned $(4,6,38)$. Ptr ToxC, the least characterized of the P. tritici-repentis

Corresponding author: L. Lamari; E-mail address: L_Lamari@umanitoba.ca

DOI: 10.1094/PHYTO-95-0144

(C) 2005 The American Phytopathological Society toxins, appears to be a low molecular weight peptide (20). Susceptibility to the necrosis component of tan spot and sensitivity to Ptr ToxA were found by several groups to be controlled by a single dominant gene $(2,21,23,46,51)$. Three dominant and independently inherited genes were shown to control sensitivity to Ptr ToxA, Ptr ToxB, and putative Ptr ToxC, one gene for each toxin (23). Ptr ToxA is produced by the overwhelming majority of isolates collected in Canada over the past two decades $(29,32)$ and appears to be the most damaging to wheat in Canada. Even though nearly half of the pathogen population of $P$. tritici-repentis is capable of causing the race 3-type chlorosis (32), attributed putatively to Ptr ToxC, most hexaploid cultivars grown in western Canada are resistant to race 3 and are assumed to be insensitive to Ptr ToxC (L. Lamari, unpublished data). Ptr ToxB does not currently represent a serious threat, because the producing races (races 5, 6, 7, and 8) are virtually absent from western Canada, except for a single low-virulence race 5 isolate $(32,50)$. The reaction of most current and historic Canadian wheat cultivars to these races of $P$. tritici-repentis and sensitivity to their toxins has not been investigated previously.

The history of wheat breeding in Canada has been relatively well documented $(17,19)$. A small number of key wheat cultivars were grown very widely over the years of wheat production in Canada and also were used extensively as parents in the development of modern wheat cultivars. The first of these key cultivars was Red Fife, which was brought into western Canada in 1868 or 1869 and was the basis of wheat production until it was supplanted by Marquis shortly after its distribution to farmers in 1909 (19). Marquis was a popular cultivar both in Canada and the United States and, by 1928 , represented $>90 \%$ of all the hard red 
spring wheat grown in Western Canada and parts of the United States (22). Marquis had the high quality of its parent, Red Fife, but was earlier maturing and became widely used in breeding programs in Canada and throughout the world (19). Stem rust epidemics during the 1930s caused the replacement of the stem-rustsusceptible Marquis by the stem-rust-resistant cv. Thatcher, registered in 1935 (19). Thatcher overtook Marquis as the predominant wheat cultivar in Canada in 1939 and remained the most popular cultivar until 1968, occupying between 30 and $70 \%$ (average of $52 \%$ ) of the total annual wheat acreage in western Canada during each of these years. The third of these influential Canadian wheat cultivars was Neepawa (registered in 1969), which was the dominant wheat cultivar in western Canada between 1973 and 1985, occupying between 43 and $68 \%$ (average of 57\%) of the total annual wheat acreage in western Canada. Other important wheat cultivars in western Canada included Selkirk, which was grown extensively from 1956 to 1968, Manitou (dominant in 1968 to 1972), Katepwa (dominant in 1986 to 1993), and AC Barrie, the current dominant cultivar. To retain the desirable characteristics of grain quality, disease resistance, and good agronomic performance, many Canadian wheat cultivars were derived from one of these key cultivars.

Approximately 10 to 14 million hectares of wheat are seeded annually in western Canada, and spring wheat accounts for $>96 \%$ of this production (19). Spring wheat in western Canada currently is divided into five quality classes: Canadian western red spring (CWRS), Canadian western amber durum (CWAD), Canadian prairie spring (CPS), Canadian western extra strong (CWES), and Canadian western soft white spring (CWSWS). The largest of these classes, CWRS, accounted for $\approx 60$ to $72 \%$ of the wheat acreage in western Canada, CWAD accounted for 20 to $28 \%$, and CPS accounted for 4 to 8\% between 1998 and 2002 (Canadian Wheat Board Statistics). Historically, the CWRS-type wheat cultivars have occupied an even larger proportion the total wheat area in western Canada relative to the other types of wheat. The CPS wheat class, established in 1985, is based on high-yielding semidwarf germ plasm and is genetically distinct from the CWRS wheat class $(19,56)$.

The advances made in tan spot of wheat provide us with the opportunity to investigate the historic development of wheat cultivars in Canada as it relates to susceptibility to tan spot. Many breeding lines and wheat cultivars that played important roles in wheat production on the Canadian prairies over the last century were tested for their sensitivity to Ptr ToxA and Ptr ToxB and their reactions to two races of $P$. tritici-repentis. The objectives of this study were to (i) characterize the major Canadian wheat cultivars for sensitivity to two toxins of $P$. tritici-repentis and susceptibility to their producing isolates, (ii) identify the origin or origins of susceptibility to tan spot in Canadian wheat, and (iii) understand the factors that led to the emergence of $P$. tritici-repentis as a major pathogen of wheat in western Canada.

\section{MATERIALS AND METHODS}

Terminology. In this report, the terms sensitivity or insensitivity and susceptibility or resistance are used to describe reactions to the toxin and to the fungus, respectively. For the sake of conciseness and clarity, sensitivity and insensitivity will be used in this article in relation to host reaction to the toxins and will imply susceptibility and resistance, respectively, to the producing isolates $(23,30)$.

Cultivars and lines. Eighty-six lines and cultivars were selected for the study based on the availability of the seed at the Cereal Research Centre (Agriculture and Agri-Food Canada, Winnipeg) germ plasm collection and on their genealogical position in the ancestries of CWRS and CPS Canadian wheat. These included 4 check lines, 6 CPS cultivars, 46 CWRS cultivars, and 30 germ plasm lines that were not registered as cultivars in Canada but were important genetic contributors to Canadian wheat. A genealogical "map" of Canadian wheat lines (19) was used as the basis for the selection. The check lines Salamouni (insensitive to all known Ptr toxins), 6B365 (sensitive to putative Ptr ToxC only), Glenlea (sensitive to Ptr ToxA only), and 6B662 (sensitive to Ptr ToxB only) were included in all tests as controls.

Plant material. Seedlings were grown in clay pots containing a soil/sand/peat mixture $(2: 2: 1$, vol/vol). Five to six seed were planted in each pot and placed in walk-in growth rooms. For the duration of the experiments, the growth rooms were maintained at 20 and $18^{\circ} \mathrm{C}$ (day and night, respectively) and a 16-h photoperiod. Light intensity was approximately $350 \mu \mathrm{E} \mathrm{m}^{-2} \mathrm{~s}^{-1}$. Seedlings were watered as needed.

Toxin production and infiltration. Ptr ToxA (necrosis-inducing) and Ptr ToxB (chlorosis-inducing) were produced and processed as described previously $(3,49)$ from isolates 86-124 (race 2) and Alg3-24 (race 5), respectively. Culture filtrates and purified toxins were stored at $-20^{\circ} \mathrm{C}$ until used. Before use, filtrates were thawed, passed through a Whatman no. 3 filter paper, and then through a Millipore membrane $(0.45 \mu \mathrm{m})$. The filtrates were diluted to 1:50 (filtrate:water) for Ptr ToxA and to 1:25 for Ptr ToxB, based on preliminary toxin activity tests. The same batches of culture filtrates and purified toxins were used throughout the study. Approximately 40 to $80 \mu \mathrm{l}$ of culture filtrates were infiltrated into leaves of seedlings using a "Hagborg" device (26). All infiltrations were performed on two-leaf-stage seedlings (12 to 15 days old). Following infiltration, seedlings were kept on a growth room bench until rated for reaction to the toxins, 3 to 4 days later. Toxin reactions were scored as + or - for the presence or absence, respectively, of the expected symptom (necrosis for Ptr ToxA and chlorosis for Ptr ToxB).

Infiltrations were performed on separate sets for each toxin. A set consisted of 86 wheat genotypes, including the controls. Each genotype was planted in two pots, each containing 5 to 6 seedlings (10 to 12 seedlings/genotype). When segregating or mixed genotypes were identified, 30 to 100 seedlings (depending on seed availability) were grown and leaves were infiltrated with the appropriate toxin to determine more precisely the segregation (mixture) ratio. The infiltration experiment was carried out three times for all genotypes, except for Atlas 66, Sonora 64, Tobari 66, BW15, CT262, Ladoga, and Carazinho, which were tested once, and Hard Red Calcutta, which was tested twice. To ensure that the reactions to the culture filtrates were similar to those induced by the purified toxins, four to six seedlings from each of the 86 genotypes used in this study were infiltrated with purified Ptr ToxA $(0.5 \mu \mathrm{g} / \mathrm{ml})$ and Ptr ToxB $(0.5 \mu \mathrm{g} / \mathrm{ml})$. Culture filtrates were used primarily in this study for logistical reasons because the repeated infiltration of a large number of leaves with purified toxin would have required larger quantities of purified toxins than could be produced practically in our laboratory.

Inoculum and inoculation. Isolates 86-124 (race 2, producer of Ptr ToxA) and Alg3-24 (race 5, producer of Ptr ToxB), representing two simple races of $P$. tritici-repentis (48), were used in this study. Conidia were produced on V8-potato dextrose agar, harvested, and mixed in a blender for $30 \mathrm{~s}$ at low speed (28). Inoculum concentration was adjusted to $\approx 3,000$ conidia/ml with sterile distilled water. Prior to inoculation, one drop of Tween 20 (polyoxyetylene sorbitan monolaurate) was added per $100 \mathrm{ml}$ of suspension to reduce surface tension.

Plants were sprayed with the spore suspension until run-off, using a deVilbiss-type sprayer, operated at an air pressure of $\approx 67 \mathrm{kPa}$. After inoculation, plants were placed in a misting chamber, where continuous leaf wetness was provided for $24 \mathrm{~h}$ by two ultrasonic humidifiers. The plants then were transferred to a growth room and set at temperature and light regimes as described above, until rated 6 to 7 days later on a scale of 1 to 5 (28).

Because of limitations of space in the misting chamber, the inoculation experiment was divided into runs of $\approx 20$ genotypes in 
duplicate pots (i.e., 40 pots/isolate). Glenlea, Salamouni, 6B365, and 6B662, described above, were used as checks in each run. A water control treatment (distilled water amended with 1 drop of Tween $20 / 100 \mathrm{ml}$ ) was included. The inoculation experiment was repeated twice.

\section{RESULTS}

In all, 86 genotypes were infiltrated with Ptr ToxA and Ptr ToxB and inoculated with isolates 86-124 (Ptr ToxA-producer) and Alg3-24 (Ptr ToxB-producer). In all experiments, the checks Glenlea, 6B662, 6B365, and Salamouni produced the expected reactions to the toxins and isolates used in this study (Table 1). All genotypes that were sensitive to Ptr ToxA also were susceptible to 86-124 and vice versa. Similarly, all genotypes sensitive to Ptr ToxB were susceptible to Alg3-24 and vice versa. Some genotypes were found to be heterogeneous for sensitivity to either Ptr ToxA or Ptr ToxB. The reactions of all wheat genotypes to the culture filtrates were similar to those induced by purified toxins. The three repetitions carried out in the infiltration experiment produced similar results.
Sensitivity to Ptr ToxA. The six CPS cultivars tested all were found to be insensitive to Ptr ToxA and resistant to 86-124, except AC Vista, which was sensitive to Ptr ToxA and susceptible to 86-124. Within the CWRS wheat lines, Red Fife, the first major spring wheat cultivar grown in Canada, was found to be sensitive to Ptr ToxA and susceptible to its producing isolate, 86-124 (race 2) (Table 1; Fig. 1). Marquis, a cultivar derived from a cross between Red Fife and Hard Red Calcutta, also was sensitive to Ptr ToxA. The sensitivity of Marquis could have come from either parent, because Hard Red Calcutta also was sensitive to Ptr ToxA (Table 1; Fig. 1), representing the second source. The third confirmed source of sensitivity to Ptr ToxA appears to have originated from the tetraploid wheat Yaroslav Emmer (Table 1; Fig. 1), one of the progenitors of the historic cv. Hope produced in the United States (40). In Canada, several Ptr ToxA-insensitive cultivars were released from crosses involving Marquis or Hope and other progenitors in the late 1920s and the 1930s. These include Reward in 1928, Thatcher (1935), Renown (1937), and Regent (1939). In 1936, a Ptr ToxA-sensitive cultivar (Apex) was released in Canada from a cross involving Ptr ToxA-sensitive Marquis (Fig. 1). The sensitivity to

TABLE 1. Reaction of 86 wheat genotypes to Ptr ToxA, Ptr ToxB and their producing isolates (86-124 and Alg 3-24) of Pyrenophora tritici-repentis ${ }^{\mathrm{a}}$

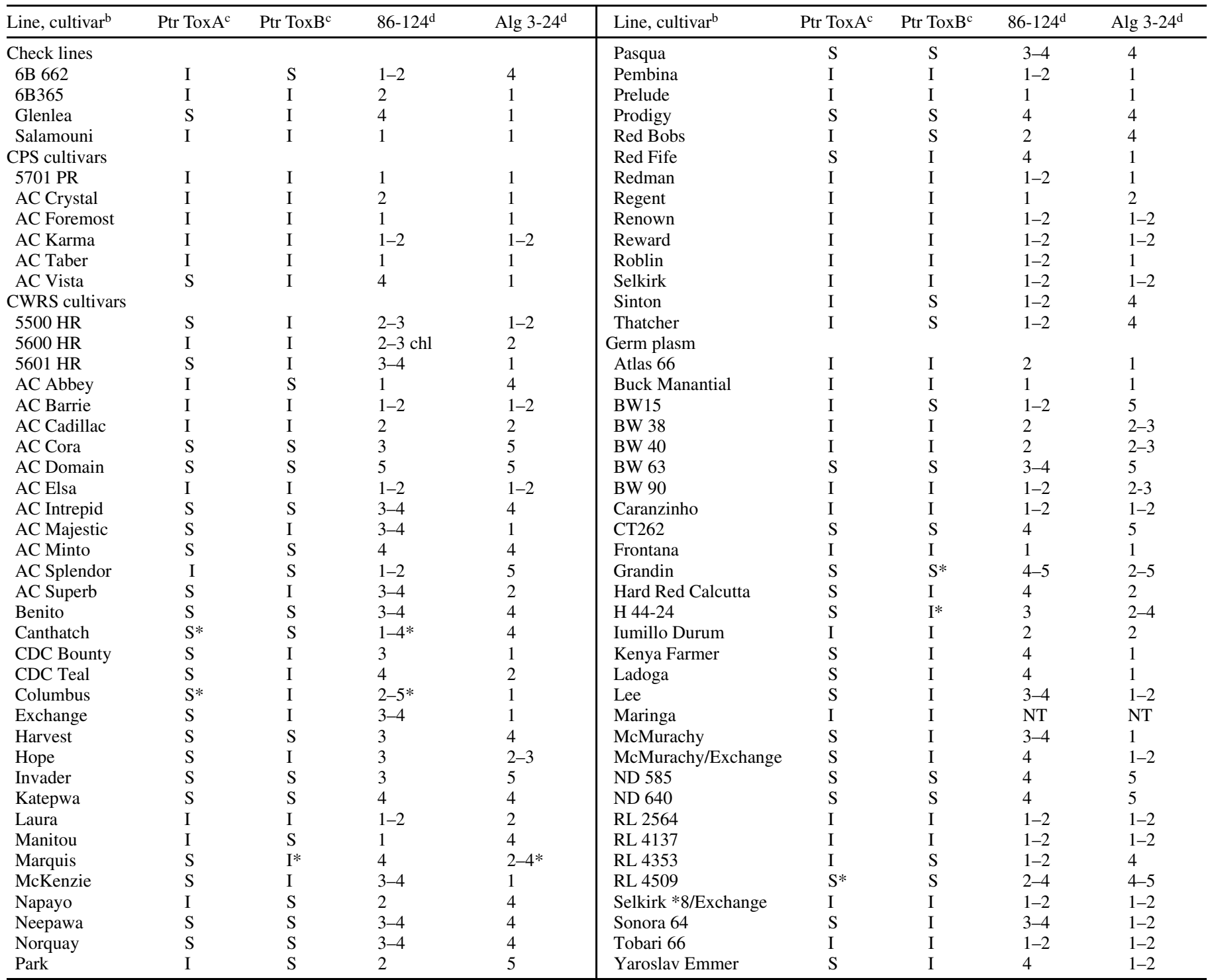

${ }^{a}$ Asterisk $(*)$ indicates a heterogeneous reaction due to seed mixture or segregation.

${ }^{\mathrm{b}} \mathrm{CPS}=$ Canadian prairie spring wheat and CWRS $=$ Canadian western red spring wheat.

${ }^{\mathrm{c}}$ Reaction to toxin: $\mathrm{S}=$ sensitive, $\mathrm{I}=$ insensitive.

d Reaction to the fungus: 1 to $2=$ resistant, $3=$ moderately resistant to moderately susceptible, 4 to $5=$ susceptible. Chl $=$ chlorotic reaction and NT $=$ not tested. 
Ptr ToxA of Apex could have originated from Red Fife, Hard Red Calcutta (through Marquis), or Yaroslav Emmer (through line H-44) (Fig. 1).

Sensitivity to Ptr ToxA in Canadian wheat lines, mostly absent in cultivars grown in the 1940s and 1950s (primarily Thatcher), was reintroduced from cv. Kenya Farmer in the 1950s, when Canthatch (Fig. 1) was produced. Kenya Farmer represents the fourth identifiable source of sensitivity to Ptr ToxA in CWRS wheat line (Table 1).

The Ptr ToxA sensitivity of Neepawa (Fig. 1) could have come only from Kenya Farmer, because Frontana and Thatcher were found in this study to be insensitive to Ptr ToxA (Table 1). Ptr ToxA sensitivity then was transferred to Benito, Katepwa, and Columbus, which were mainly backcross progenies of Neepawa (Fig. 1). The sensitivity to Ptr ToxA observed in many modern Canadian cultivars (1990s and 2000s) was mostly inherited from Neepawa and its derivatives (Fig. 1).

A group of modern susceptible cultivars involving material from North Dakota appears to be consistently sensitive to Ptr ToxA. The sensitivity of Canadian cvs. AC Domain, Harvest, and AC Superb could have originated from ND585 (pedigree: Butte*3/ND507), ND640 (pedigree: RL4352-1/Butte), and Grandin (pedigree: Lenana//Butte*2/ND-507/3/ND-593), which also were found to be sensitive to Ptr ToxA (Fig. 1). The expanded pedigrees of the North Dakota germ plasm ND499, ND585, ND640, and Grandin (data not shown) suggest that sensitivity to Ptr ToxA in these lines could have originated from Red Fife, Hard Red Calcutta, or Yaroslav Emmer sources, because they have occurrences of Marquis and Hope in their backgrounds.

Sensitivity to Ptr ToxB. All CPS wheat cultivars tested were insensitive to Ptr ToxB and resistant to Alg3-24 (Table 1). The origin of Ptr ToxB sensitivity in CWRS wheat was more problematic to ascertain. Initial tests of Marquis indicated that one of two batches of this cultivar was heterogeneous for reaction to Ptr ToxB and the other was insensitive. Following the testing of Hard Red Calcutta (acquired late in the study) and the finding that it was insensitive to Ptr ToxB, a third batch of Marquis from a different source (M. Entz, Department of Plant Science, University of Manitoba, Canada) was tested and also found to be insensitive to Ptr ToxB. Given the insensitive reactions of both Hard Red Calcutta and Red Fife, it is likely that the heterogeneity of Marquis was due to previous out-crossing or a seed mixture in one of the seed batches. Furthermore, there are many strains of Marquis and reselections within the cultivar. In this study, sensitivity to Ptr ToxB appeared unambiguously in Thatcher, which was found to be homogeneously sensitive in all tests.

The sensitivity of Thatcher, a major cultivar in Canada and the United States (produced in Minnesota), was likely inherited from Kanred Winter (not tested), because Iumillo Durum and Marquis, the other parents of Thatcher, were found to be insensitive to Ptr ToxB (Fig. 2; Table 1). Later, cvs. Saunders (1947), Canthatch (1959), Park (1963), and Manitou (1965) inherited sensitivity to Ptr ToxB from Thatcher (Fig. 2). Neepawa, a cultivar developed from parents that were backcross derivatives of Thatcher, also was found to be sensitive to Ptr ToxB. Sensitivity then was transferred to several Neepawa-derived cultivars and lines, including Katepwa, Benito, BW63. and several of their derivatives registered between 1990 and 2003 (Fig. 2).

AC Domain and its derivative Harvest were sensitive to Ptr ToxB and susceptible to race 5 (Table 1). These cultivars have in their immediate parentage several genotypes from North Dakota (ND 585 and ND 640), also found to be sensitive to Ptr ToxB. Ptr ToxB sensitivity in this group may have originated from Thatcher, a genotype present in the expanded pedigree of AC Domain. Superb was found to be insensitive to Ptr ToxB, whereas both of its parents were sensitive (Fig. 2). Following this finding, 20 individual prebreeder lines (the original Superb), kindly provided by Stephen Fox (Cereal Research Centre, Agriculture and Agri-Food
Canada, Winnipeg, Canada), were tested for reaction to $\mathrm{Ptr}$ ToxA and Ptr ToxB as well as isolates 86-124 and Alg3-24. All 20 lines were found to be homogeneously sensitive to $\mathrm{Ptr}$ ToxA and insensitive to Ptr ToxB (susceptible to 86-124 and resistant to $\mathrm{Alg} 3-24)$, confirming the reactions observed on Superb (Table 1).

A group of Canadian cultivars (AC Barrie, AC Cadillac, AC Elsa, and Laura) produced at SPARC (Agriculture and Agri-Food Canada, Swift Current, SK, Canada) were insensitive to Ptr ToxA and Ptr ToxB (Figs. 1 and 2, lower-right quadrant). These were produced following a strategy of intercrossing genetically diverse materials followed by selection for resistance to "leaf spots" rather than by intensive backcrossing to Neepawa (R. M. dePauw, unpublished data).

Cultivar statistics. Data on the area occupied by various cultivars in western Canada between 1939 and 2003 was compiled from different sources (Searle Grain, 1939-1940; Line Elevator Farm Service, 1941-1966; Federal Grain Ltd., 19661971; Prairie Wheat Pools, 1972-1992; Secan, 1993; and the Canadian Wheat Board, 1998-2003). The relative proportions of the most significant cultivars (representing 5\% or more of the total wheat area) were used to compute, for each year, the percentage of the crop with sensitivity to Ptr ToxA and Ptr ToxB (Fig. 3).

\section{DISCUSSION}

The six CPS wheat cultivars tested were insensitive to $\mathrm{Ptr}$ ToxA, resistant to 86-124, insensitive to Ptr ToxB, and resistant to Alg3-24. The only exception was AC Vista, which was sensitive to Ptr ToxA and susceptible to 86-124. The CPS wheat lines are genetically distinct from CWRS wheat cultivars and are derived from the CIMMYT-based semidwarf cv. HY320 (19,56). The cultivars tested represent some of the predominant cultivars grown from this class. Overall, this wheat class appears to be primarily insensitive to Ptr ToxA and Ptr ToxB and resistant to isolates 86124 and Alg 3-24, used in this study.

Sensitivity to Ptr ToxA and Ptr ToxB, two host-specific toxins produced by $P$. tritici-repentis, was successfully surveyed in CWRS wheat lines representing a period of more than a century, from Red Fife, the first major Canadian spring wheat, to the most recently released cultivars. With a few exceptions, the reactions of all the genotypes tested in this study to Ptr ToxA and Ptr ToxB were consistent with their parental lineage and mostly predictable: a cultivar was sensitive to a given toxin if both parents were sensitive, and vice versa. This predictability reflects the Mendelian nature of wheat reaction to tan spot and to the known fact that sensitivity to the toxins is controlled by single, dominant genes $(2,21,23,30,31,46,51)$ and independently inherited, one gene for each toxin (23).

The unexpected Ptr ToxB-insensitivity of Superb, derived from a cross between sensitive AC Domain and Grandin (Fig. 2), is attributed to the heterogeneity of Grandin. Grandin is known to be heterogeneous for reaction to leaf rust (26). Furthermore, Superb was found to lack Lr34 (B. D. McCallum, unpublished data), a gene conditioning adult plant resistance to leaf rust, when both Grandin (35) and AC Domain (36) are known to carry the gene. We were not able to secure seed from the original plant of Grandin that was used in the cross with AC Domain to produce Superb. However, we could "posthumously" assume that it lacked Lr34 and the gene for sensitivity to Ptr ToxB.

A few cultivars were heterogeneous for sensitivity to the toxins. Canthatch was found to be homogeneous for reaction to Ptr ToxB (all sensitive) but heterogeneous for reaction to Ptr ToxA (16\% sensitive) (Table 1). A similar situation was reported previously, and confirmed in the present study, for cv. Columbus, which was found to consist of two morphologically indistinguishable types with differing reactions to Ptr ToxA (30). One of two seed batches 
of Marquis obtained from the Cereal Research Center (AAFC, Winnipeg, Canada) was heterogeneous for reaction to Ptr ToxB ( $\approx 5 \%$ sensitive). A third source of Marquis was tested and found to be insensitive to Ptr ToxB, a reaction consistent with that of both parents (Fig. 2). It is likely that the heterogeneous batch of Marquis consisted of a seed mixture. A similar situation was encountered with line H-44 (Fig. 2), which was found to be heterogeneous for reaction to $\mathrm{Ptr} \operatorname{ToxB}(<5 \%$ sensitive) and believed to be a seed mixture.

Sensitivity to Ptr ToxA and Ptr ToxB in Canadian wheat appears to have originated from a small number of sources. Sensitivity was present very early in the Canadian wheat program and maintained for more than a century through reuse of genetic material and intensive backcrossing to recover good cereal quality and superior adaptation. The most significant era appears to be that of Thatcher-Canthatch, when sensitivity to Ptr ToxA was reintroduced from Kenya Farmer, after it had almost disappeared from the crop in western Canada (Figs. 1 and 3). The production of Neepawa (sensitive to both toxins), and its ubiquitous use in the production of Marquis/Thatcher-type rust-resistant cultivars during the past 30 years, represents a critical breeding decision in the history of tan spot in Canadian wheat. The importance of Neepawa was noted by Mercado et al. (42), who found that Neepawa and the semidwarf CPS cv. HY 320 were the most commonly used named parents of wheat cultivars released in Canada between 1981 and 1991. The introgression of susceptibility evidently was unintentional, because tan spot was not a perceived problem in Canada prior to 1970. However, the overreliance on a limited number of progenitors and the intensive back- crossing to primarily maintain superior cereal quality may have kept the genetic diversity of CWRS wheat dangerously narrow. In fact, the genetic diversity of CWRS wheat may have diminished over time (56). A relatively narrow genetic base for field crops can lead to unanticipated and severe epidemics, such as the southern leaf blight that devastated the Tcms-based maize hybrid cultivars in the United States in the 1970s (55). A different strategy to develop CWRS cultivars has evolved at SPARC (Agriculture and Agri-Food Canada, Swift Current, Sask., Canada). The breeders used a strategy of three-way and four-way crosses to introgress novel genes into a CWRS end-use suitability package. Selection was done for leaf retention characteristics contributed by resistance to leaf spots. Also, simultaneous selection for grain yield and grain protein content was applied. The impact is evident in cvs. AC Barrie, AC Cadillac, AC Elsa, and Laura, which are not only resistant to Ptr ToxA and Ptr ToxB but also have higher grain yield and protein content than Neepawa (18).

The success of Marquis led to the development of other historically significant cultivars in the United States, such as Hope, Thatcher, and Ceres. In fact, Red Fife, directly or through Marquis, permeated North American hard red spring wheat breeding programs more than any other cultivar in the past century, accounting for $18 \%$ of the cultivars' origins in Canada and the United States between 1901 and 1991 (42). Although the analysis of cultivars from the United States is beyond the present study, sensitivity to Ptr ToxA in many U.S. cultivars may have originated from the same sources (i.e., Red Fife, Hard Red Calcutta, Yaroslav Emmer, and Kenya Farmer) as that of their Canadian counterparts.

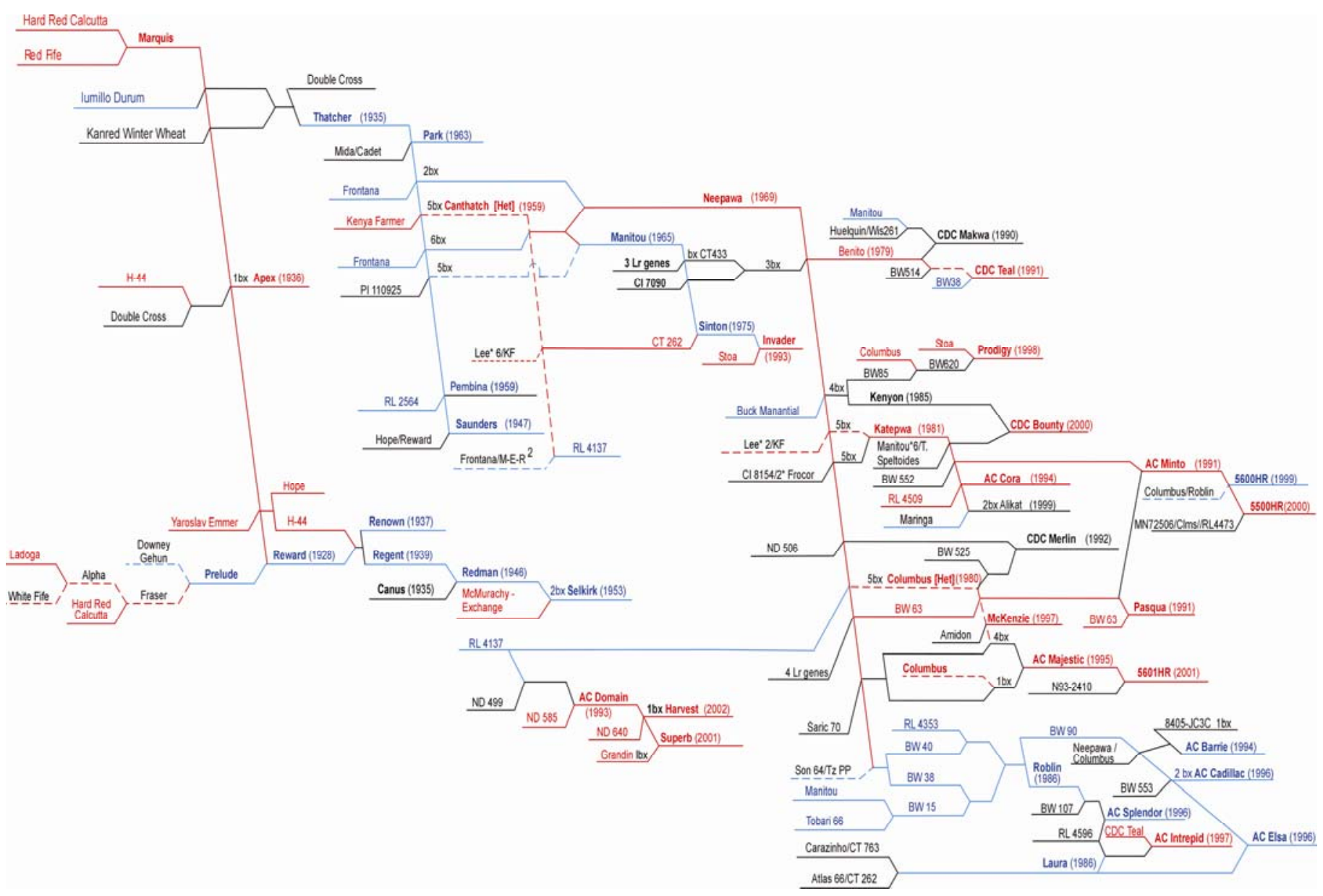

Fig. 1. Sensitivity of Canadian Western Red Spring wheat lines and germ plasm to necrosis-inducing Ptr ToxA host-selective toxin of Pyrenophora tritici-repentis. Black lines and text: genotypes not tested; red solid lines and text: genotypes sensitive to Ptr ToxA; blue solid lines and text: genotypes insensitive to Ptr ToxA; color dashed lines (red or blue): predicted sensitivity (red) or insensitivity (blue) based on known parental or progeny reactions. [Het] $=$ heterogeneous reaction due to seed mixture or segregation; bx = backcross. 
In spite of the continuous presence of susceptible wheat cultivars (Figs. 1 and 2), epidemics of tan spot were not common in the Canadian Prairies for almost a century, until the 1970s. Marquis, released in $1909(17,19,44)$, dominated the North American agricultural landscape for at least 25 years and remained the predominant cultivar in western Canada until 1938, when it was gradually replaced by stem-rust-resistant cultivars (e.g., Thatcher). Marquis eventually disappeared from Manitoba and Saskatchewan between 1947 and 1950 (25), but still represented $3.5 \%$ of the hard red spring wheat grown in Alberta in 1955 (22). Based on historical precedence of epidemics of plant diseases such as Victoria blight of oats (Cochliobolus victoriae) (41) or southern leaf blight of maize (C. heterostrophus (Drechs.) Drechs.) (27, $55)$, tan spot of wheat should have emerged during the Red FifeMarquis era (1880 to 1939). In fact, P. tritici-repentis rose to epidemic levels during this period $(10,11)$. Conidia and pseudothecia of $P$. tritici-repentis first were identified in Canada from stubble of Marquis wheat in southern Saskatchewan in 1927 (9). The fungus was identified from living plants in 1934 when it was found on Elymus canadensis in southern Manitoba (9) and first was reported on living wheat plants in 1937 (10). There were reports of unidentified wheat leaf spot consisting of "small brown spots with light borders" in South Alberta in 1928 (39) and wheat leaf spots of undetermined nature across western Canada in 1930 (14), 1932 (7), and 1933 (8). This strongly suggests that $P$. triticirepentis may have been part of the "leaf spot complex" for many years prior to 1937 because other common leaf-spotting diseases such as spot blotch (C. sativus), glume blotch (Phaeosphaeria nodorum), and speckled leaf blotch (Mycosphaerella graminicola) were well known in these survey reports. In 1939, Pyrenophora tritici-repentis was found at epidemic levels on wheat crops throughout southern Manitoba (10). The tan spot outbreaks of 1937 and 1939 in Manitoba, apparently the first recorded major epidemics of tan spot in wheat in North America, were attributed to the "considerable increase in the use of one-way disc, which fails to cover stubble with soil as does the mould-board plough" (J. E. Machacek cited by I. L. Conners) (11), a stubble-retention hypothesis similar to that formulated for the modern tan spot epidemic (43). Tan spot was reported in trace amounts in 1940 (12), at epidemic levels in west-central Saskatchewan in 1941, and at slighter levels in southwestern Manitoba (13). Occurrences were reported in 1944 (15) and 1964 (16), then reached epidemic proportions on a regular basis in the 1970s (52). Thus, it would appear that warnings of impending epidemics were present relatively early, but epidemics were perhaps not of great concern compared with other diseases. Wheat breeding in the first half of the twentieth century was dominated by the rusts, which represented far greater threats to the crop than any emerging leaf blotch disease.

Following the introduction of tan-spot-resistant cvs. Thatcher (1935) and Selkirk (1953), the area covered by Ptr ToxA-sensitive cultivars was considerably reduced (Fig. 3) and, by 1960, represented $<1 \%$ of the total hard spring wheat area of western Canada. It is unlikely that races 1 and 2, the currently predominant races (32), would have been selected by the crop and increased during this period. The fact that epidemics of tan spot

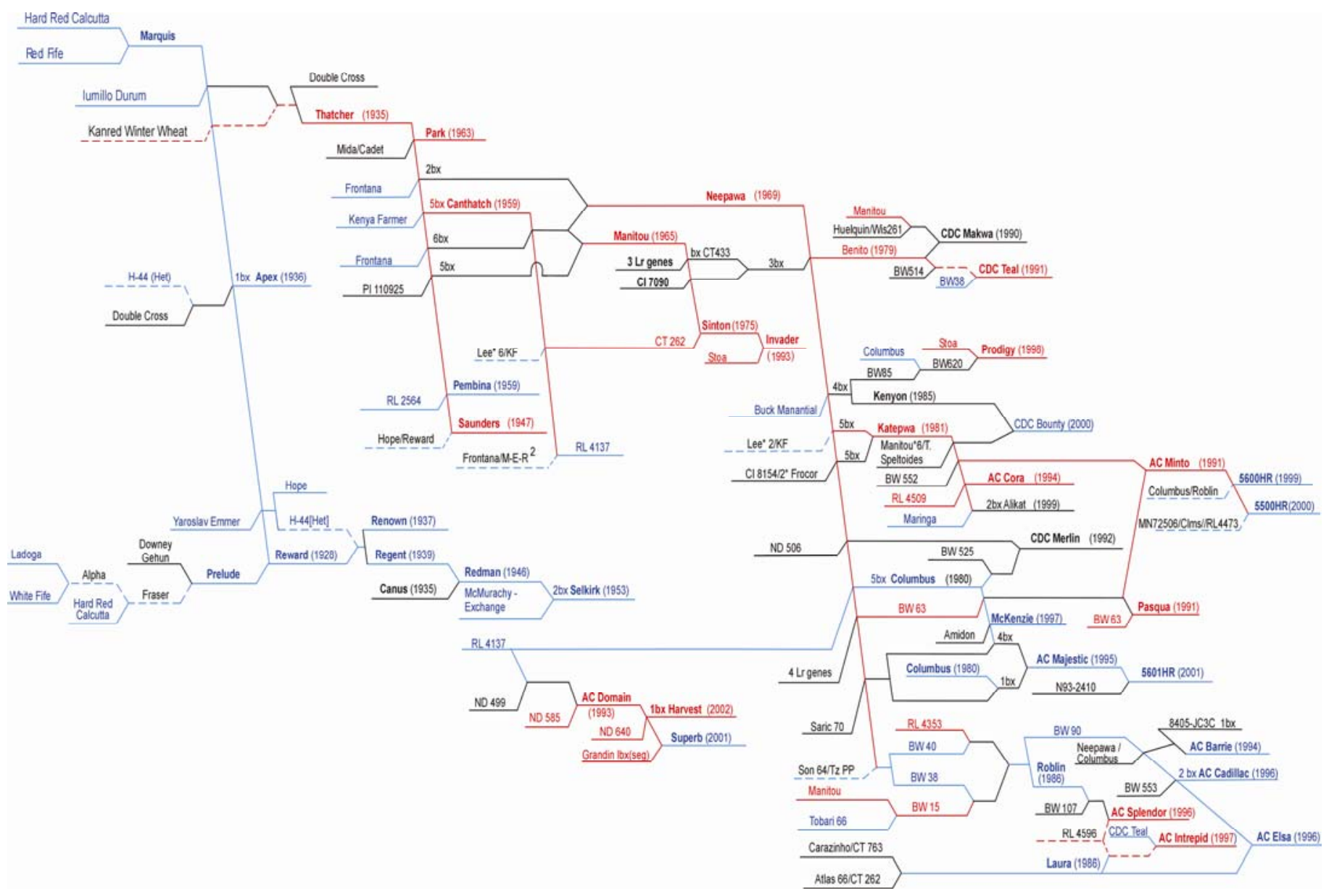

Fig. 2. Sensitivity of Canadian Western Red Spring wheat lines and germ plasm to chlorosis-inducing Ptr ToxB host-selective toxin of Pyrenophora triticirepentis. Black lines and text: genotypes not tested; red solid lines and text: genotypes sensitive to Ptr ToxB; blue solid lines and text: genotypes insensitive to Ptr ToxB; colored dashed lines (red or blue): predicted sensitivity (red) or insensitivity (blue) based on known parental or progeny reactions. [Het] $=$ heterogeneous reaction due to seed mixture or segregation; bx = backcross. 
were not reported after the removal of Ptr ToxA-sensitive Marquis and other sensitive cultivars suggests that host resistance may have played a role in controlling the disease for several decades. Epidemics restarted when sensitivity to Ptr ToxA was reintroduced on a large scale in the 1970s (e.g., the Neepawa era).

The emergence of race 15B of Puccinia graminis $\mathrm{f}$. sp. tritici in western Canada in the mid 1940s (24), to which Thatcher was susceptible, led wheat breeders to use Kenya Farmer in their programs to produce rust-resistant Canthatch in 1959 and Neepawa in 1969 (Fig. 1), resulting in the unintentional reintroduction of susceptibility to tan spot (Ptr ToxA sensitivity) into the mainstream Canadian wheat cultivars (Fig. 1). It is not clear from the results of this study if the sensitivity of Kenya Farmer (pedigree: Gaza/5/2*Blount's Lambrigg//Red Fife/Sinew/3/Red Fife/HR/4/ SWD/6/Button/Kenya 73D2I1C) came from Red Fife, which appears in the pedigree, or from another source. The dominance of Neepawa and its derivatives coincided with the tan spot epidemics of the early 1970s (Fig. 3), the first account of which was reported by Tekauz (52). The results obtained in this study do not contradict the findings of Rees and Platz (43), linking the development of tan spot in Australia to changing agronomic practices toward stubble retention. The deep plowing, stubble burning, summer fallow, and crop rotations in the Marquis era (1909 to 1939), which were greatly reduced during the Neepawa era (1973 to 1985), likely prevented the buildup of inoculum by depriving the fungus of its overwintering habitat. However, in addition to differences in stubble management, a second major difference between the Marquis and Neepawa eras appears to be stem rust resistance. Although both cultivars were susceptible to tan spot, Marquis gained popularity for agronomic and quality traits but suffered from stem rust susceptibility, whereas Neepawa and its derivatives were resistant to stem rust. We were not able, in the present study, to identify a clear genetic linkage between rust resistance and susceptibility to tan spot, similar to the one previously reported for the $P c 2$ resistance gene $(P$. coronata) and the $V b$ gene for sensitivity to victorin (C. victoriae) (57). However, we suspected that, in the case of Neepawa and its derivatives,

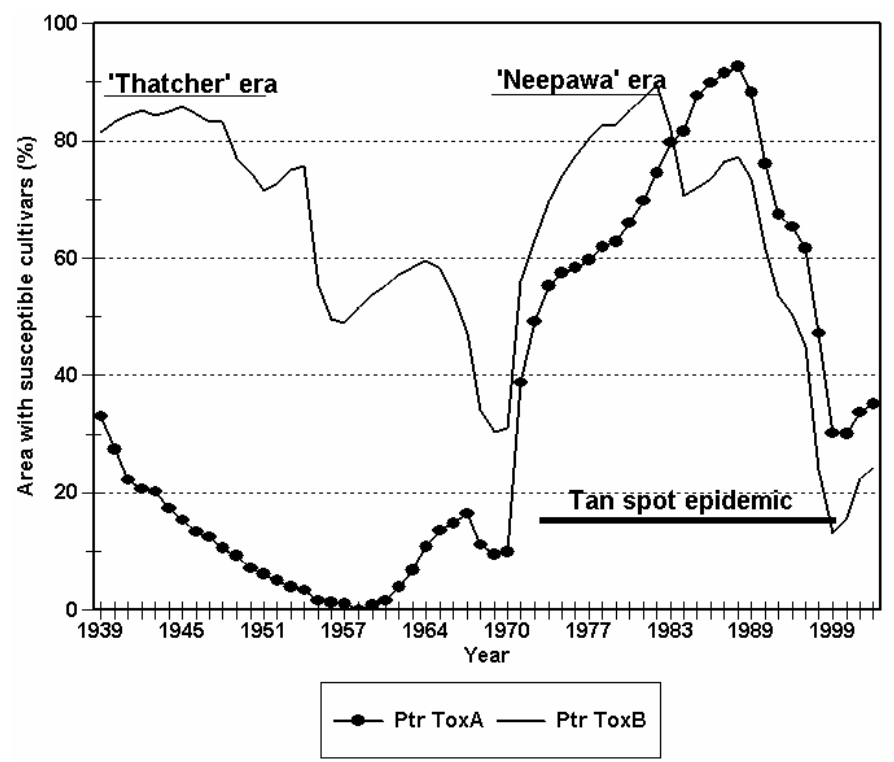

Fig. 3. Sensitivity to Ptr ToxA and Ptr ToxB in the wheat crop produced in western Canada from 1939 to 2003. For each year, values were computed as the ratio of cumulative area occupied by toxin-sensitive cultivars to the total Canadian Western Red Spring (CWRS) wheat area. Only cultivars grown on at least $5 \%$ of the CWRS wheat area in western Canada were considered. Wheat cultivar production data compiled from annual surveys of western Canada done by Searle Grain (1939-1940), Line Elevator Farm Service (1941-1966), Federal Grain Ltd. (1966-1971), Prairie Wheat Pools (1972-1992), Secan (1993), and the Canadian Wheat Board (1998-2003). resistance to rust could have provided a relatively "clean" leaf for colonization by an opportunistic pathogen, such as Pyrenophora tritici-repentis. The rust resistance hypothesis, though speculative, is consistent with the synchronous rise of tan spot observed in North America and Australia because, by the 1960s, these two major wheat-producing regions had successfully deployed rustresistant cultivars on a very wide scale. A study by Roelfs (45) found that stem rust epidemics nearly disappeared by the decade 1968 to 1977 as a result of the barberry eradication program and the introduction of resistant cultivars in 13 states in the United States. The data of Roelfs (45) easily could apply to western Canada, which underwent similar programs.

The absence of Ptr ToxB-producing isolates in western Canada is puzzling, given that sensitivity to $\mathrm{Ptr}$ ToxB was present for several decades in Canadian wheat (Fig. 3). Intuitively, Ptr ToxBproducing races (races 5, 6, 7, and 8) should have been selected by the crop, if these races were present in western Canada. Presently, we have evidence of the presence in race 3 (from Canada) of the coding, but not the promoter, region of ToxB, the gene encoding Ptr ToxB (G. M. Ballance, personal communication). Race 4 (avirulent) carries a gene with $86 \%$ homology to ToxB $(37,47,48)$. Races 3 and 4 are very rare in Canada and do not produce any detectable level of active Ptr ToxB. So far, only a single low-virulence race 5 isolate (50) was ever collected in more than 15 years of field surveys conducted in western Canada $(29,32$; L. Lamari unpublished data). The millions of hectares cultivated continuously with Ptr ToxB-sensitive cultivars over more than 70 years should have provided ample opportunity for the crop to select wild-type Ptr ToxB-producing isolates, such as those found in North Africa (33), the Fertile Crescent, and the Caucasus (34). The absence of wild-type race 5 isolates in western Canada is in contrast with their isolation from durum wheat in North Dakota (1), a neighboring state with climatic, ecological, and agricultural similarities. We currently are conducting studies to explain this apparent epidemiological puzzle.

The results of the present study clearly indicated that host susceptibility to $P$. tritici-repentis, a necessary condition for disease development, was present in western Canada for many decades before the 1970 s epidemic. It is difficult to predict whether the situation would have been fundamentally different had the genetic base been more variable. However, our data strongly suggest that the reliance on a rather limited number of genotypes in some Canadian wheat-breeding programs resulted in the production, by chance, of a highly susceptible crop. Conversely, a breeding strategy based on intercrossing of different genetic materials resulted in the recent release of a large group of resistant cultivars (AC Barrie, AC Cadillac, AC Elsa, and Laura), representing more than $40 \%$ of the currently grown wheat in western Canada since 1999.

This case study of the response of the historical Canadian wheat gene pool to two races of $P$. tritici-repentis highlights the need for a holistic approach to all the diseases present in an agroecological area. An over-emphasis on one disease may lead to genetic vulnerability to another disease. Likewise, it underscores the need to have several genetic enhancement programs, each using different genetic materials and breeding strategies, as a mechanism to increase the probability of genetic preservation of a major economic crop.

\section{ACKNOWLEDGMENTS}

We thank the Natural Sciences and Engineering Research Council of Canada (NSERC) for financial support to L. Lamari; R. B. Smith (University of Manitoba) and J. Hoeppner (CRC, AAFC Winnipeg) for technical help; S. Fox and T. Romanow (CRC, AAFC Winnipeg) for kindly providing seed of many test lines, including pre-breeder seed of Superb; and M. Mergoum (North Dakota State University, Fargo) for providing the pedigrees of some North Dakota wheat lines. 


\section{LITERATURE CITED}

1. Ali, S., Francl, L. J., and DeWolf, E. D. 1999. First report of Pyrenophora tritici-repentis race 5 from North America. Plant Dis. 83:591.

2. Anderson, J. A., Effertz, R. J., Faris, J. D., Francl, L. J., Meinhardt, S. W., and Gill, B. S. 1999. Genetic analysis of sensitivity to a Pyrenophora tritici-repentis necrosis-inducing toxin in durum and common wheat. Phytopathology 89:293-297.

3. Ballance, G. M., Lamari, L., and Bernier, C. C. 1989. Purification and characterization of a host-selective necrosis toxin from Pyrenophora tritici-repentis. Physiol. Mol. Plant Pathol. 35:203-213.

4. Ballance, G. M., Lamari, L., Kowatsch, R., and Bernier, C. C. 1996. Cloning, expression and occurrence of the gene encoding the Ptr necrosis toxin from Pyrenophora tritici-repentis. Mol. Plant Pathol. Online, publication/1996/1209/ballance.

5. Ciuffetti, L. M., Francl, L. J., Ballance, G. M., Bockus, W. W., Lamari, L., Meinhardt, S. W., and Rasmussen, J. B. 1998. Standardization of toxin nomenclature in the Pyrenophora tritici-repentis/wheat interaction. Can. J. Plant Pathol. 20:421-424.

6. Ciuffetti, L. M., Tuori, R. P., and Gaventa, J. M. 1997. A single gene encodes a selective toxin causal to the development of tan spot of wheat. Plant Cell. 9:135-144.

7. Conners, I. L. 1932. Page 8 in: 12th Annu. Rep. Can. Plant Dis. Surv. Canada Department of Agriculture, Experimental Farms Branch.

8. Conners, I. L. 1933. Page 6 in: 13th Annu. Rep. Can. Plant Dis. Surv. Canada Department of Agriculture, Dominion Experimental Farms Branch.

9. Conners, I. L. 1934. Page 100 in: 14th Annu. Rep. Can. Plant Dis. Surv. Canada Department of Agriculture, Experimental Farms Branch.

10. Conners, I. L. 1937. Page 5 in: 17th Annu. Rep. Can. Plant Dis. Surv. Canada Department of Agriculture. Division of Botany and Plant Pathology.

11. Conners, I. L. 1939. Pages 12-14 in: 19th Annu. Rep. Can. Plant Dis. Surv. Canada Department of Agriculture. Division of Botany and Plant Pathology.

12. Conners, I. L. 1940. Page 3 in: 20th Annu. Rep. Can. Plant Dis. Surv. Canada Department of Agriculture. Division of Botany and Plant Pathology.

13. Conners, I. L. 1941. Page 6 in: 21st Annu. Rep. Can. Plant Dis. Surv. Canada Department of Agriculture. Division of Botany and Plant Pathology.

14. Conners, I. L., and Eardley, E. A. 1930. Page 12 in: 10th Annu. Rep. Prevalence Plant Dis. in the Dominion of Canada. Canada Department of Agriculture, Experimental Farms Branch.

15. Conners, I. L., and Savile, D. B. O. 1944. Page 5 in: 4th Annu. Rep. Can. Plant Dis. Surv. Canada Department of Agriculture. Division of Botany and Plant Pathology.

16. Creelman, D. W. 1964. Diseases of cereal crops. Can. Plant Dis. Surv. 44:15-21

17. DePauw, R. M., Boughton, G. R., and Knott, D. R. 1995. Hard red spring wheat. Pages 5-35 in: Harvest of Gold-The History of Field Crop Breeding in Canada. A. E. Slinkard and D. R. Knott, eds. University Extension Press, University of Saskatchewan, Canada.

18. DePauw, R. M., Clarke, J. M., McCaig, T. N., and Townley-Smith, F. T. 1998. Opportunities for improvement of western Canadian protein concentration, grain yield and quality through plant breeding. Pages 75-93 in: Wheat Protein Production and Marketing. D. B. Fowler, W. E. Geddes, A. M. Johnston, and K. R. Preston, eds. University Extension Press, Saskatoon, SK, Canada.

19. DePauw, R., and Hunt, T. 2001. Canadian Wheat Pool. Pages 479-515 in: The World Wheat Book, A History of Wheat Breeding. A. P. Bonjean and W. J. Angus, eds. Lavoisier Publishing, Paris.

20. Effertz, R. J., Meinhardt, S. W., Anderson, J. A., Jordahl, J. G., and Francl, L. J. 2002. Identification of a chlorosis-inducing toxin from Pyrenophora tritici-repentis and the chromosomal location of an insensitivity locus in wheat. Phytopathology, 92:527-533.

21. Faris, J. D., Anderson, J. A., Francl, L. J., and Jordahl J. G. 1996. Chromosomal location of a gene conditioning insensitivity in wheat to a necrosis-inducing culture filtrate from Pyrenophora tritici-repentis. Phytopathology 86:459-463.

22. Fraser, J. G., and Whiteside, A. G. O. 1956. Handbook of Canadian Spring Wheat Varieties. Canada Department of Agriculture, publication no. 538. Ottawa, ON, Canada.

23. Gamba, F. M., Lamari, L., and Brûlé-Babel, A. L. 1998. Inheritance of race-specific necrotic and chlorotic reactions induced by Pyrenophora tritici-repentis in hexaploid wheats. Can. J. Plant Pathol. 20:401407.

24. Goulden, C. H., and Stevenson, T. M. 1949. Breeding for disease-resistance in Canada. Part I. Cereals. Emp. J. Exp. Agric. 17:133140.
25. Greany, F. J., and Barnes, J. 1953. Distribution of Wheat Varieties in the Prairie Provinces. Line Elevators Farm Service, circ. no. 15, Winnipeg, Manitoba, Canada

26. Hagborg, W. A. F. 1970. A device for injecting solutions and suspensions into thin leaves of plants. Can. J. Bot. 48:1135-1136.

27. Hooker, A. L., Smith, D. R., Jim, S. R., and Beckett, J. B. 1970. Reaction of corn seedlings with male-sterile cytoplasm to Helminthosporium maydis. Plant Dis. Rep. 54:708-712.

28. Lamari, L., and Bernier, C. C. 1989. Evaluations of wheat lines and cultivars to tan spot (Pyrenophora tritici-repentis) based on lesion type. Can. J. Plant Pathol. 11:49-56.

29. Lamari, L., and Bernier, C. C. 1989. Virulence of isolates of Pyrenophora tritici-repentis on 11 wheat cultivars and cytology of the differential host reactions. Can. J. Plant Pathol. 11:284-290.

30. Lamari, L., and Bernier, C. C. 1989. Toxin of Pyrenophora triticirepentis: Host-specificity, significance in disease, and inheritance of hostreaction. Phytopathology 79:740-744.

31. Lamari, L., and Bernier, C. C. 1991. Genetics of tan necrosis and extensive chlorosis in tan spot of wheat caused by Pyrenophora triticirepentis. Phytopathology 81:1092-1095.

32. Lamari, L., Gilbert, J., and Tekauz, A. 1998. Race differentiation in Pyrenophora tritici-repentis and survey of physiologic variation in western Canada. Can. J. Plant Pathol. 20:396-340.

33. Lamari, L., Sayoud, R., Boulif, M., and Bernier, C. C. 1995. Identification of a new race in Pyrenophora tritici-repentis: Implications for the current pathotype classification system. Can. J. Plant Pathol. 17:312318.

34. Lamari, L., Strelkov, S. E., Yahyaoui, A., Orabi, J., and Smith, R. B. 2003. The identification of two new races of Pyrenophora tritici-repentis from the host centre of diversity confirms a one-to-one relationship in tan spot of wheat. Phytopathology 93:391-396.

35. Liu, J. Q., and Kolmer, J. A. 1997. Inheritance of leaf rust resistance in wheat cultivars Grandin and CDC Teal. Plant Dis. 81:505-508.

36. Liu, J., and Kolmer, J. A. 1997. Genetics of leaf rust resistance in Canadian spring wheat varieties AC Domain and AC Taber. Plant Dis. 81:757-760.

37. Martinez, J. P., Oesch, N. W., and Ciuffetti, L. M. 2004. Characterization of the multiple-copy host-selective toxin gene, ToxB, in pathogenic and nonpathogenic isolates of Pyrenophora tritici-repentis. Mol. PlantMicrobe Interact. 17:467-474.

38. Martinez, J. P., Ottum, S. A., Ali, S., Francl, L. J., and Ciuffetti, L. M. 2001. Characterization of the ToxB gene from Pyrenophora triticirepentis. Mol. Plant-Microbe Interact. 14:675-677.

39. McCurry, J. B. 1929. Page 12 in: Report on the Prevalence of Plant Diseases in the Dominion of Canada for the years 1927 and 1928. Canada Department of Agriculture, Division of Botany, Dominion Experimental Farms.

40. McFadden, E. S. 1930. A successful transfer of emmer characters to vulgare wheat. Agron. J. 22:1020-1034.

41. Mehan, F., and Murphy, H. C. 1946. A new Helminthosporium blight of oats. Science 104:413-414.

42. Mercado, L. A., Souza, E., and Kephard, K. D. 1996. Origin and diversity of North American hard spring wheats. TAG 93:593-599.

43. Rees, R. G., and Platz, G. J. 1992. Tan spot and its control-Some Australian experiences. Pages 1-9 in: Advances in Tan Spot Research: Proc. 2nd Int. Tan Spot Workshop. L. J. Francl, J. M. Krupinsky, and M. P. McMullen, eds. N. D. Agric. Exp. Stn. Fargo, ND.

44. Reitz, L. P. 1954. Wheat breeding and our food supply. Econ. Bot. 8:251268.

45. Roelfs, A. P. 1982. Effect of Barberry eradication on stem rust in the United States. Plant Dis. 66:177-181.

46. Stock, W. S., Brûlé-Babel, A. L., and Penner, G. A. 1996. A gene for resistance to a necrosis-inducing isolate of Pyrenophora tritici-repentis located on 5BL of Triticum aestivum cv. Chinese Spring. Genome 39:598604.

47. Strelkov, S. E. 2002. Occurrence and expression of ToxB and comparative virulence of chlorosis inducing races of Pyrenophora tritici-repentis. $\mathrm{Ph} . \mathrm{D}$. thesis, The University of Manitoba.

48. Strelkov, S. E., and Lamari, L. 2003. Host-parasite interactions in tan spot (Pyrenophora tritici-repentis) of wheat. Can. J. Plant Pathol. 25:339349.

49. Strelkov, S. E., Lamari, L., and Ballance, G. M. 1999. Characterization of a host-specific protein toxin (Ptr ToxB) from Pyrenophora tritici-repentis. Mol. Plant-Microbe Interact. 12:728-732.

50. Strelkov, S. E., Lamari, L., Sayoud, R., and Smith, R. B. 2002. Comparative virulence of chlorosis-inducing races of Pyrenophora tritici-repentis. Can. J. Plant Pathol. 24:29-35.

51. Sykes, E. E., and Bernier, C. C. 1991. Qualitative inheritance of tan spot resistance in hexaploid, tetraploid, and diploid wheat. Can. J. Plant Pathol. 13:38-44. 
52. Tekauz, A. 1976. Distribution, severity and relative importance of leaf spot disease of wheat in western Canada in 1974. Can. Plant Dis. Surv. 56:36-40.

53. Tomás, A., Feng, G. H., Reeck, G. R., Bockus, W. W., and Leach, J. E. 1990. Purification of a cultivar-specific toxin from Pyrenophora triticirepentis, causal agent of tan spot of wheat. Mol. Plant-Microbe Interact. 8:41-48.

54. Tuori, R. P., Wolpert, T. J., and Ciuffetti, L. M. 1995. Purification and immunological characterization of toxin components from cultures of Pyrenophora tritici-repentis. Mol. Plant-Microbe Interact. 8:41-48.
55. Ullstrup, A. J. 1972. The impacts of the southern corn leaf blight epidemics of 1970-1971. Helminthosporium turcicum. Annu. Rev. Phytopathol. 10:37-50.

56. Van Beuningen, L. T., and Bush, R. H. 1997. Genetic diversity among North American spring wheat cultivars: I. Analysis of the coefficient of parentage matrix. Crop Sci. 37:570-579.

57. Welsh, J. N., Peturson, B., and Machacek, J. E. 1954. Associated inheritance of reaction to races of crown rust, Puccinia coronata avenae Erikss. and to Victoria blight, Helminthosporium victoriae M. and M., in oats. Can. J. Bot. 32:55-68. 